\title{
Dietary corn resistant starch regulates intestinal morphology and barrier functions by activating the Notch signaling pathway of broilers
}

\author{
Yingying Zhang ${ }^{1}$, Yingsen Liu', Jiaolong $\mathrm{Li}^{1}$, Tong Xing ${ }^{1}$, Yun Jiang ${ }^{2}$, Lin Zhang ${ }^{1, *}$, and Feng Gao ${ }^{1, *}$
}

\author{
* Corresponding Authors: \\ Lin Zhang \\ Tel: +86-25-84399007, Fax: +86-25-84395314, \\ E-mail: zhanglin2012@njau.edu.cn \\ Feng Gao \\ Tel: +86-25-84399007, Fax: +86-25-84395314, \\ E-mail: gaofeng0629@sina.com
}

${ }^{1}$ College of Animal Science and Technology, Key Laboratory of Animal Origin Food Production and

Safety Guarantee of Jiangsu Province, Jiangsu

Collaborative Innovation Center of Meat Production

and Processing, Quality and Safety Control, Joint

International Research Laboratory of Animal Health and Food Safety, National Experimental Teaching

Demonstration Center of Animal Science, Nanjing

Agricultural University, Nanjing 210095, China

${ }^{2}$ School of Food Science and Pharmaceutical

Engineering, Nanjing Normal University, Nanjing

210097, China

ORCID

Yingying Zhang

https://orcid.org/0000-0002-4303-6527

Yingsen Liu

https://orcid.org/0000-0001-9609-1215

Jiaolong Li

https://orcid.org/0000-0002-6967-6784

Tong Xing

https://orcid.org/0000-0003-1561-4614

Yun Jiang

https://orcid.org/0000-0002-1195-1843

Lin Zhang

https://orcid.org/0000-0003-1555-1086

Feng Gao

https://orcid.org/0000-0002-5415-7922

Submitted Dec 20, 2019; Revised Jan 24, 2020; Accepted Feb 21, 2020
Objective: This study was conducted to investigate the effects of dietary corn resistant starch (RS) on the intestinal morphology and barrier functions of broilers.

Methods: A total of 320 one-day-old broilers were randomly allocated to 5 dietary treatments: one normal corn-soybean (NC) diet, one corn-soybean-based diet supplementation with $20 \%$ corn starch (CS), and 3 corn-soybean-based diets supplementation with $4 \%$, $8 \%$, and $12 \%$ corn resistant starch (RS) (identified as $4 \%$ RS, $8 \%$ RS, and $12 \%$ RS, respectively). Each group had eight replicates with eight broilers per replicate. After 21 days feeding, one bird with a body weight (BW) close to the average BW of their replicate was selected and slaughtered. The samples of duodenum, jejunum, ileum, caecum digesta, and blood were collected.

Results: Birds fed 4\% RS, 8\% RS and 12\% RS diets showed lower feed intake, BW gain, jejunal villus height (VH), duodenal crypt depth (CD), jejunal VH/CD ratio, duodenal goblet cell density as well as mucin 1 mRNA expressions compared to the NC group, but showed higher concentrations of cecal acetic acid and butyric acid, percentage of jejunal proliferating cell nuclear antigen-positive cells and delta like canonical Notch ligand 4 (Dll4), and hes family bHLH transcription factor 1 mRNA expressions. However, there were no differences on the plasma diamine oxidase activity and D-lactic acid concentration among all groups.

Conclusion: These findings suggested that RS could suppress intestinal morphology and barrier functions by activating Notch pathway and inhibiting the development of goblet cells, resulting in decreased mucins and tight junction mRNA expression.

Keywords: Corn Resistant Starch; Intestinal Morphology; Barrier Function; Broiler

\section{INTRODUCTION}

The small intestine is not only responsible for digestion and absorption of nutrients, but also plays critical roles in mucosal barrier functions, signal recognition and production of some endogenous biological active molecules [1-3]. Intact mucosal development and barrier functions are essential for intestinal health. Diet is one of the important factors shaping intestinal mucosal morphology and barrier functions. Starch serves as a major source of carbohydrates in poultry diets, which can be classified into rapidly digestible starch, slowly digestible starch and resistant starch (RS) according to its digestion and absorption rates in small intestine [4]. RS, which acts as dietary fibre, could resist digestion in small intestine and thus reach the large intestine where short chain fatty acids are produced by gut microbiota [5]. Therefore, RS exerts a prebiotic influence on mammalian intestinal health [6,7].

Complete mucosal morphology is the premise of normal intestinal digestion and absorption. Some animal studies have shown that dietary RS supplementation can increase 
the villus height $(\mathrm{VH})[8]$, decrease crypt depth (CD), and promote $\mathrm{VH} / \mathrm{CD}$ ratio [9]. It's well known that the continuous renewal of intestinal epithelium is the result of the proliferation of crypt cells and their transfer to the top of villi, and then these crypt cells gradually differentiate into cells with various physiological functions such as absorption or secretion in the process of transfer [10]. Notch is a major regulatory pathway that determines the fate of cell differentiation of cryptic stem cells $[2,11,12]$. There are four core elements in the Notch signaling system, Notch receptor, Delta/Serrate/Lag2 (DSL) ligands, CBF-1, Su(H), Lag-1 (CSL) transcriptional cofactors, and target genes such as the hairy/enhancer of split (HES) genes family [13]. Notch activity affects the implementation of differentiation, proliferation, and apoptotic programs [14]. Generally, Notch inhibition leads to precocious differentiation of epithelial progenitors into secretory cell types, including large numbers of cells that expressed both Paneth and goblet cell markers [12].

There are four main cell types in intestinal epitheliums, including absorptive enterocytes, goblet cells, Paneth cells, and enteroendocrine cells [15]. among which goblet cells play a critical role in maintaining the intestinal barrier function via synthesizing and secreting mucin glycoproteins (MUC1, MUC2, MUC3, MUC17) [16,17]. The higher proliferation rate of intestinal epithelium is associated with lower differentiation and maturation, which may affect the physiological functions of the small intestine $[18,19]$. Different from mammals, birds have a shorter digestive tract and weaker microbial fermentation [20]. Although some achievements have been obtained in the studies on humans and mammals, little is known on how dietary RS affects intestinal morphology and barrier functions of poultry. Therefore, this study aimed to investigate the effects of dietary grade levels of corn RS on growth performance, intestinal morphology and barrier functions, as well as the changes of Notch pathway in intestinal mucosa of broilers.

\section{MATERIALS AND METHODS}

\section{Ethics statements}

All animal work was carried out according to the approved guidelines established by the Ministry of Agriculture of China. All experimental design and procedures were approved by the Institutional Animal Care and Use Committee of Nanjing Agricultural University (GB14925, NJAU-CAST-2011-093).

\section{Animals and experimental design}

A total of 320 newly hatched one-day-old Arbor Acres broiler chicks were purchased from a commercial hatchery (Hewei Agricultural Development Co. Ltd, Xuancheng, China). Chicks were weighed and randomly assigned to five dietary treatments: one normal corn-soybean (NC) diet, one corn- soybean-based diet supplementation with $20 \%$ corn starch (CS) (maize starch, 99\% purity, YuXing Inc., Hebei, China), and 3 corn-soybean-based diets supplementation with $4 \%$, $8 \%$, and $12 \%$ corn RS (identified as $4 \%$ RS, $8 \%$ RS, and $12 \%$ RS, respectively) by replacing CS with $6.67 \%, 13.33 \%$, and $20 \%$ of Hi-Maize 260 (type II RS, 60\% purity; Ingredion Inc., Westchester, IL, USA), respectively. All diets were formulated to satisfy the nutritional requirements according to the National Research Council (NRC, 1994). The composition and nutrition levels of all diets are given in Table 1. Each treatment group had eight replicates (one replicate per cage) with eight broilers per replicate. The birds were given free access to feed and water in a temperature-controlled room at Nanjing Kangxin Poultry Industry (Nanjing, China) throughout a 21-d experiment. On 21 days, birds were weighed per replicate cage, and feed consumption was recorded by replicate to calculate the feed intake, body weight (BW) gain and feed/gain (F/G).

\section{Sample collection}

At 21 days of age, one bird with a BW close to the average BW of each replicate was selected, weighed, stunned electrically and slaughtered immediately via exsanguination of the left carotid artery. Approximately $5 \mathrm{~mL}$ of blood samples were collected into heparinized tubes and centrifuged immediately to get plasma. After evisceration, the small intestine of birds was carefully separated into three segments: duodenum (from ventriculus to the pancreo-biliary duct), jejunum (from pancreo-biliary duct to yolk stalk), and ileum (from yolk stalk to ileocecal junction). The contents of each part was washed with pre-cold saline and weighted to calculate intestine index (relative weight $=$ intestine weight, $\mathrm{g} / \mathrm{BW}$, kg; relative length $=$ intestine length, $\mathrm{cm} / \mathrm{BW}, \mathrm{kg}$ ). Approximately $1 \mathrm{~cm}$ of the middle portion of each intestinal segment were collected and fixed in $4 \%$ phosphate-buffered paraformaldehyde for morphological analysis. The mucosa of duodenal, jejunal and ileal was then gently scraped and digesta of the caecum from each bird were mixed and collected, frozen in liquid nitrogen and stored at $-80^{\circ} \mathrm{C}$ for further analysis.

\section{Intestinal morphology}

Intestinal samples were embedded in paraffin and cross sections $(5 \mu \mathrm{m})$ were cut and stained with hematoxylin-eosin (HE) staining. Images were captured using an Olympus DP12 CCD digital camera (Olympus Optical Co. Ltd, Tokyo, Japan) and analyzed by Image-Pro Plus 6.0 software (Media Cybernetics, Bethesda, MD, USA) to measure the $\mathrm{VH}(\mu \mathrm{m}$, from the tip of villus to the villus-crypt junction level for 10 villi per section) and $\mathrm{CD}(\mu \mathrm{m}$, the vertical distance from the villus-crypt junction to the lower limit of the crypt for 10 corresponding crypts per section). The ratio of $\mathrm{VH}$ to $\mathrm{CD}(\mu \mathrm{m} / \mu \mathrm{m})$ was also calculated. 
Table 1. Ingredients and nutrient composition of experimental diets (as fed basis)

\begin{tabular}{|c|c|c|c|c|c|}
\hline \multirow{2}{*}{ Items } & \multicolumn{5}{|c|}{ Treatments $^{1)}$} \\
\hline & NC & CS & $4 \% \mathrm{RS}$ & $8 \% \mathrm{RS}$ & $12 \% \mathrm{RS}$ \\
\hline \multicolumn{6}{|l|}{ Ingredients (\%) } \\
\hline Soybean meal (44\% crude protein) & 31.50 & 28.15 & 28.15 & 28.15 & 28.15 \\
\hline Corn gluten meal (63.5\% crude protein) & 3.40 & 8.15 & 8.15 & 8.15 & 8.15 \\
\hline Corn starch & - & 20.00 & 13.33 & 6.67 & - \\
\hline Soybean oil & 3.10 & 2.20 & 2.20 & 2.20 & 2.20 \\
\hline Limestone & 1.20 & 1.20 & 1.20 & 1.20 & 1.20 \\
\hline Dicalcium phosphate & 2.00 & 2.00 & 2.00 & 2.00 & 2.00 \\
\hline L-lysine & 0.34 & 0.34 & 0.34 & 0.34 & 0.34 \\
\hline DL-methionine & 0.15 & 0.15 & 0.15 & 0.15 & 0.15 \\
\hline Metabolizable energy (MJ/kg) & 12.52 & 12.50 & - & - & - \\
\hline Crude protein (\%) & 21.33 & 21.00 & 21.00 & 21.00 & 21.00 \\
\hline Calcium $(\%)$ & 1.00 & 1.00 & 1.00 & 1.00 & 1.00 \\
\hline Available phosphorus (\%) & 0.46 & 0.45 & 0.45 & 0.45 & 0.45 \\
\hline Lysine $(\%)$ & 1.21 & 1.12 & 1.12 & 1.12 & 1.12 \\
\hline Methionine (\%) & 0.50 & 0.51 & 0.51 & 0.51 & 0.51 \\
\hline Methionine + cysteine (\%) & 0.86 & 0.85 & 0.85 & 0.85 & 0.85 \\
\hline Arginine (\%) & 1.27 & 1.18 & 1.18 & 1.18 & 1.18 \\
\hline Threonine (\%) & 0.83 & 0.81 & 0.81 & 0.81 & 0.81 \\
\hline \multicolumn{6}{|l|}{ Analysed nutrient levels } \\
\hline
\end{tabular}

1) NC, a basic normal corn-soybean diet; CS, a corn-soybean-based diet supplementation with 20\% corn starch (CS); 4\% RS, 8\% RS, and 12\% RS, the corn-soybean-based diets supplementation with $4 \%, 8 \%$, and $12 \%$ corn resistant starch (RS), respectively.

2) Premix provided per kilogram of diet: trans-retinyl acetate, $30 \mathrm{mg}$; cholecalciferol, $0.075 \mathrm{mg}$; DL-a-tocopherol acetate, $30 \mathrm{mg}$; menadione, $1.3 \mathrm{mg}$; thiamine, $2.2 \mathrm{mg}$; riboflavin, 8.0 mg; nicotinamide, 40 mg; choline, 400 mg; pantothenic acid (D-Ca pantothenate), 15 mg; pyridoxine HCl, 4mg; biotin, 0.04 mg; folic acid, 1 mg; cobalamin, 0.013 mg; Fe (from ferrous sulphate), 80 mg; Cu (from copper sulphate), 8.0 mg; Mn (from manganese sulphate), 110 mg; Zn (from zinc sulphate), 60 mg; I (from calcium iodate), 1.1 $\mathrm{mg}$; Se (from sodium selenite), $0.3 \mathrm{mg}$.

\section{Goblet cell counts}

Intestinal cross sections from the samples embedded in paraffin were stained with Alcian Blue and periodic acid-Schiff reagent (Sigma, St. Louis, MO, USA) for goblet cell counts. The microscopic image of each sample was examined at a final magnification of $\times 200$. The density of goblet cell was defined as the goblet cell count per $100 \mu \mathrm{m}$ villus length (n/per $100 \mu \mathrm{m}$ villus). The average values of the density of goblet cells of 6 villus from duodenum, jejunum and ileum cross sections per chicken were used.

\section{Proliferating cell nuclear antigen immunohistochemistry} Immunohistochemical analysis was used to evaluate expression of proliferating cell nuclear antigen (PCNA)-positive cells. Cross sections $(5 \mu \mathrm{m})$ of each bird were deparaffinized in xylene, dehydrated in a graded series of alcohol and rehy- drated in phosphate buffer saline (PBS) ( $\mathrm{pH}$ 7.4). Then, the sections were pre-treated by a microwave, treated with $3 \%$ hydrogen peroxide and incubated with primary antibody (Anti-PCNA mouse monoclonal antibody, 1:200 dilution; Bio Basic Canada Inc, Markham, ON, Canada) overnight at $4^{\circ} \mathrm{C}$. After washing with PBS, the sections were incubated with the second antibody (Goat Anti-Mouse IgG for IHC/ HRP; Bio Basic Canada Inc, Canada) for 45 min then washed again and treated with a diaminobenzidine staining kit (K5007; Angle Gene Bioengineering Co. Ltd., Nanjing, China), then finally counter-stained with hematoxylin. The analysis was carried out on histological slides at a final magnification of $\times 400$. Approximately 200 cells in the middle portion of the well-oriented villus in the section were evaluated. The percentage of PCNA-positive cells for each villus was calculated as the number of PCNA-positive cells divided by the total 
number of cells counted, multiplied by 100 . Values represent the mean of 6 villi from each bird.

\section{RNA extraction andreal-time quantitative polymerase} chain reaction analysis

Total RNA was isolated from the duodenal and jejunal mucosa samples using Trizol reagent (Takara Biotechnology Co. Ltd., Dalian, China). The purity and quantity of the RNA were measured with a Nanodrop ND-1000 spectrophotometer (Thermo Scientific, Wilmington, DE, USA). Reverse transcription of total RNA was completed using a PrimeScript RT Master Mix kit (Takara Biotechnology, China). The RT products (cDNA) were stored at $-20^{\circ} \mathrm{C}$. Real-time quantitative polymerase chain reaction (RT-qPCR) was performed using the QuanStudio6 RT-qPCR detection system (Applied Biosystems, Foster City, CA, USA) using SYBR Premix Ex Taq kits (Takara Biotechnology, China). The following cycling conditions were used: $95^{\circ} \mathrm{C}$ for $30 \mathrm{~s}$, followed by 40 cycles of denaturation at $95^{\circ} \mathrm{C}$ for $5 \mathrm{~s}$ and anneal at $60^{\circ} \mathrm{C}$ for $30 \mathrm{~s}$, and the collection of the fluorescence signal at $60^{\circ} \mathrm{C}$. All the specific primers used are listed in Table 2. The expression of target genes relative to $18 \mathrm{~S}$ rRNA was calculated using the $2^{-\Delta \Delta \mathrm{CT}}$ method [21].

\section{Analysis of plasma diamine oxidase activity and D-lactic acid concentration}

The diamine oxidase (DAO) activity and D-lactic acid concentration in plasma were determined with the commercial diagnostic kits (Catalog numbers: H263 and A088-1-1, respectively; Nanjing Jiancheng Bioengineering Institute, Nanjing, China) according to the manufacturer's instructions.

\section{Short-chain fatty acids analyses Approximately $0.3 \mathrm{~g}$ frozen cecal digesta was diluted with 5 -fold double-distilled water in sterile Eppendorf tubes. The sample solutions were homogenized and centrifuged (15 min, $4,000 \times g)$. Supernatant $(1.0 \mathrm{~mL})$ was transferred to a new Eppendorf tube and mixed with ice-cold metaphosphoric acid solution $(0.2 \mathrm{~mL} ; 25 \%$ concentration; internal standard was added, crotonic acid $75.08 \mathrm{mmol} / \mathrm{L}$ ). The solution was kept at $-20^{\circ} \mathrm{C}$ overnight and then centrifuged (10 min, 16,000 $\times g$ ). Concentrations of the short-chain fatty acids (SCFAs) were determined in the supernatant using a Gas Chromato- graphic System (Agilent 7890A, Santa Clara, CA, USA).}

\section{Statistical analysis}

All data were analyzed using one-way analysis of variance

Table 2. Primer sequences for real-time quantitative PCR analysis

\begin{tabular}{|c|c|c|c|}
\hline Genes & GenBank numbers & Primer sequences $\left(5^{\prime} \rightarrow 3^{\prime}\right)$ & Product sizes (bp) \\
\hline Mucin-1 & XM_015279046.2 & $\begin{array}{l}\text { Forward: ACGCCTTCTTCAGCAGCAACTC } \\
\text { Reverse: AGCAGCAGATGTGAGCAGTGATG }\end{array}$ & 183 \\
\hline Mucin-2 & NM_001318434.1 & $\begin{array}{l}\text { Forward: ACTGGACTTCACGGACACCT } \\
\text { Reverse: CCCCCTCTACCATCATCAAA }\end{array}$ & 121 \\
\hline Claudin-1 & NM_001013611.2 & $\begin{array}{l}\text { Forward: GACCAGGTGAAGAAGATGCGGATG } \\
\text { Reverse: CGAGCCACTCTGTTGCCATACC }\end{array}$ & 107 \\
\hline occludin & XM_025144248.1 & $\begin{array}{l}\text { Forward: CTGCTCTGCCTCATCTGCTTCTTC } \\
\text { Reverse: CCATCCGCCACGTTCTTCACC }\end{array}$ & 143 \\
\hline ZO-1 & XM_015278981.2 & $\begin{array}{l}\text { Forward: GCCAGCCATCATTCTGACTCCAC } \\
\text { Reverse: GTACTGAAGGAGCAGGAGGAGGAG }\end{array}$ & 172 \\
\hline $20-2$ & NM_204918.1 & $\begin{array}{l}\text { Forward: GAGAGCACAACCGAAGCAGAGG } \\
\text { Reverse: TAGTCCTGTCCATAGCCACCATCC }\end{array}$ & 157 \\
\hline Notch1 & NM_001030295.1 & $\begin{array}{l}\text { Forward: GACAGCATCGCCGCCTTCAC } \\
\text { Reverse: CGTCCAGGTTGATCTCGCAGTTG }\end{array}$ & 187 \\
\hline Notch2 & NM_001252033.1 & $\begin{array}{l}\text { Forward: CCAAAGCGAACCCTTGTTACC } \\
\text { Reverse: CACACCCAAGAGAAGAATCAAGAG }\end{array}$ & 94 \\
\hline DLL1 & NM_204973.2 & $\begin{array}{l}\text { Forward: CTGGTCCTCATGCTGCTGCTG } \\
\text { Reverse: CACCGATGACGCTGATGGAGATG }\end{array}$ & 166 \\
\hline DLL4 & XM_421132.6 & $\begin{array}{l}\text { Forward: GCTACTGTCCTTCTGGCTTCATGG } \\
\text { Reverse: CATCGTCTCCAAGTCCTGCTGTG }\end{array}$ & 200 \\
\hline Hes1 & XM_015291592.2 & $\begin{array}{l}\text { Forward: GGACGCGCTGAAGAAGGATAGTTC } \\
\text { Reverse: GCAGGTGCTTGACGGTCATCTC }\end{array}$ & 80 \\
\hline Atoh1 & XM_004941130.3 & $\begin{array}{l}\text { Forward: GGCTGAACCACGCCTTCGAC } \\
\text { Reverse: GCGTCTCGTACTTGGAGAGCTTC }\end{array}$ & 81 \\
\hline
\end{tabular}

ZO-1, zonula occludens-1; ZO-2, zonula occludens-2; DLL1, delta like canonical Notch ligand 1; DLL4, delta like canonical Notch ligand 4; Hes1, hes family bHLH transcription factor 1; Atoh1, atonal homolog 1. 
using SPSS software (Version 20.0, SPSS Inc., Chicago, IL, USA). The effect of increasing concentration of dietary RS was determined by orthogonal polynomial contrasts. The model included linear and quadratic contrasts for effects of supplemental RS. The results are presented as means with their standard errors. A total of eight replicate were used per treatment $(n=8)$. Significant differences were declared when $\mathrm{p}<0.05$.

\section{RESULTS}

\section{Growth performance}

As shown in Table 3, birds fed CS and RS diets had lower feed intake and BW gain than those fed the NC diet $(\mathrm{p}<0.05)$ and had higher F/G than those fed the NC diet $(\mathrm{p}<0.05)$. The feed intake increased linearly, and $F / G$ increased linearly as the proportion of dietary RS increased $(\mathrm{p}<0.05)$.

\section{Development of small intestine}

According to Table 4, birds fed CS and RS diets had higher relative lengths of small intestine (duodenum, jejunum and ileum) than those fed the NC diet ( $\mathrm{p}<0.05)$. Birds from $8 \%$ RS and $12 \%$ RS groups and those from $8 \%$ RS, and $12 \%$ RS groups had higher relative weights of duodenum and jejunum, respectively $(\mathrm{p}<0.01)$. In addition, the relative lengths and weights of duodenum increased linearly as the proportion of dietary RS increased $(\mathrm{p}<0.05)$.

\section{Intestinal morphology}

It is obvious in Table 5 , the duodenal CD of birds fed RS diets was lower than those fed NC diet $(\mathrm{p}<0.01)$. Birds of CS group and RS groups exhibited lower jejunal $\mathrm{VH}$ and $\mathrm{VH} / \mathrm{CD}$ compared with $\mathrm{NC}$ group $(\mathrm{p}<0.01)$. The ileal $\mathrm{VH}$ in groups of CS and $4 \%$ RS and the ileal CD in groups of $4 \%$ RS and $8 \%$ RS were lower than that of control $(\mathrm{p}<0.05)$. Besides, feeding RS diets linearly increased the ileal $\mathrm{VH}$, jejunal and ileal CD, duodenal VH/CD, and linearly decreased the duodenal CD $(p<0.01)$. Moreover, the jejunal VH/CD presented quadratic response to the increased RS in diets $(\mathrm{p}<0.05)$.

\section{Intestinal goblet cell density}

The Figure 1 shows that the duodenal goblet cell density (GCD) in $4 \% \mathrm{RS}, 8 \% \mathrm{RS}$, and $12 \% \mathrm{RS}$ groups were lower than that in NC group $(\mathrm{p}<0.05$, Table 6$)$, and the ileal GCD were decreased quadratically in response to the increase of dietary RS level $(\mathrm{p}<0.05)$.

Table 3. Effect of corn resistant starch on the growth performance of broilers from 0 to 21 days

\begin{tabular}{|c|c|c|c|c|c|c|c|c|c|}
\hline \multirow{2}{*}{ Items } & \multicolumn{5}{|c|}{ Treatments $^{1)}$} & \multirow{2}{*}{ SEM } & \multicolumn{3}{|c|}{$\mathrm{p}$-value } \\
\hline & NC & CS & $4 \%$ RS & $8 \%$ RS & $12 \%$ RS & & ANOVA & Linear $^{2)}$ & Quadratic $^{2)}$ \\
\hline Feed intake (g/bird) & $966.76^{a}$ & $726.68^{b}$ & $733.07^{b}$ & $761.29^{b}$ & $762.75^{b}$ & 15.96 & $<0.001$ & 0.003 & 0.788 \\
\hline BW gain (g/bird) & $678.26^{a}$ & $482.72^{b}$ & $480.06^{b}$ & $497.63^{b}$ & $471.25^{b}$ & 13.53 & $<0.001$ & 0.594 & 0.103 \\
\hline Feed/gain (g/g) & $1.43^{c}$ & $1.50^{b}$ & $1.53^{b}$ & $1.53^{b}$ & $1.62^{\mathrm{a}}$ & 0.01 & $<0.001$ & $<0.001$ & 0.005 \\
\hline
\end{tabular}

Results are represented as the mean value \pm SEM $(n=8)$.

SEM, standard error of the mean; ANOVA, analysis of variance; BW, body weight.

1) NC, a basic normal corn-soybean diet; CS, a corn-soybean-based diet supplementation with 20\% corn starch (CS); $4 \%$ RS, $8 \%$ RS, and 12\% RS, the corn-soybeanbased diets supplementation with $4 \%, 8 \%$, and $12 \%$ corn resistant starch (RS), respectively.

${ }^{2)}$ Orthogonal polynomial contrast was used to determine linear and quadratic effects of increasing concentrations of resistant starch in CS and RS diets.

${ }^{a-c}$ Means in a row without a common superscript letter significantly differ $(p<0.05)$.

Table 4. Effects of corn resistant starch on the relative length and weight of small intestine of 21-day-old broilers

\begin{tabular}{|c|c|c|c|c|c|c|c|c|c|}
\hline \multirow{2}{*}{ Items } & \multicolumn{5}{|c|}{ Treatments $^{1)}$} & \multirow{2}{*}{ SEM } & \multicolumn{3}{|c|}{$\mathrm{p}$-value } \\
\hline & NC & CS & $4 \%$ RS & $8 \%$ RS & $12 \%$ RS & & ANOVA & Linear $^{2)}$ & Quadratic ${ }^{2)}$ \\
\hline Duodenum (cm/kg BW) & $35.68^{d}$ & $41.67^{c}$ & $43.91^{b c}$ & $45.79^{\mathrm{ab}}$ & $47.57^{\mathrm{a}}$ & 0.66 & $<0.001$ & $<0.001$ & 0.822 \\
\hline Jejunum (cm/kg BW) & $78.15^{b}$ & $108.85^{\mathrm{a}}$ & $110.29^{a}$ & $113.55^{\mathrm{a}}$ & $121.95^{\mathrm{a}}$ & 3.19 & $<0.001$ & 0.126 & 0.592 \\
\hline Ileum (cm/kg BW) & $73.81^{b}$ & $108.85^{\mathrm{a}}$ & $110.38^{a}$ & $112.73^{\mathrm{a}}$ & $121.96^{\mathrm{a}}$ & 3.40 & $<0.001$ & 0.155 & 0.579 \\
\hline Duodenum (g/kg BW) & $6.88^{b}$ & $6.87^{b}$ & $6.51^{b}$ & $8.10^{\mathrm{a}}$ & $8.50^{\mathrm{a}}$ & 0.16 & $<0.001$ & $<0.001$ & 0.196 \\
\hline Jejunum (g/kg BW) & $16.23^{b}$ & $17.94^{\mathrm{ab}}$ & $18.23^{\mathrm{a}}$ & $19.83^{\mathrm{a}}$ & $19.04^{\mathrm{a}}$ & 0.75 & 0.002 & 0.108 & 0.293 \\
\hline Ileum (g/kg BW) & 12.23 & 12.45 & 12.97 & 13.03 & 14.55 & 1.33 & 0.178 & 0.068 & 0.511 \\
\hline
\end{tabular}

Results are represented as the mean value $\pm \operatorname{SEM}(n=8)$.

SEM, standard error of the mean; ANOVA, analysis of variance; BW, body weight.

1) NC, a basic normal corn-soybean diet; CS, a corn-soybean-based diet supplementation with 20\% corn starch (CS); 4\% RS, $8 \%$ RS, and $12 \%$ RS, the corn-soybean-based diets supplementation with $4 \%, 8 \%$, and $12 \%$ corn resistant starch (RS), respectively.

${ }^{2)}$ Orthogonal polynomial contrast was used to determine linear and quadratic effects of increasing concentrations of resistant starch in CS and RS diets.

${ }^{a-d}$ Means in a row without a common superscript letter significantly differ $(p<0.05)$. 
Table 5. Effect of corn resistant starch on the intestinal morphology of 21-day-old broilers

\begin{tabular}{|c|c|c|c|c|c|c|c|c|c|}
\hline \multirow{2}{*}{ Items } & \multicolumn{5}{|c|}{ Treatments $^{1)}$} & \multirow{2}{*}{ SEM } & \multicolumn{3}{|c|}{$p$-value } \\
\hline & NC & CS & $4 \%$ RS & $8 \% \mathrm{RS}$ & $12 \%$ RS & & ANOVA & Linear $^{2)}$ & Quadratic $^{2 l}$ \\
\hline \multicolumn{10}{|l|}{ Duodenum } \\
\hline VH ( $\mu \mathrm{m})$ & 839.60 & 840.12 & 800.98 & 836.23 & 813.06 & 14.97 & 0.893 & 0.709 & 0.625 \\
\hline $\mathrm{CD}(\mu \mathrm{m})$ & $107.50^{a}$ & $107.08^{\mathrm{a}}$ & $87.89^{b}$ & $89.58^{b}$ & $82.75^{b}$ & 2.56 & $<0.001$ & $<0.001$ & 0.118 \\
\hline $\mathrm{VH} / \mathrm{CD}(\mu \mathrm{m} / \mu \mathrm{m})$ & 8.48 & 8.28 & 8.93 & 9.62 & 9.51 & 0.19 & 0.067 & 0.006 & 0.235 \\
\hline \multicolumn{10}{|l|}{ Jejunum } \\
\hline $\mathrm{VH}(\mu \mathrm{m})$ & $705.68^{a}$ & $663.84^{c}$ & $681.17^{b}$ & $670.78^{\mathrm{bc}}$ & $679.31^{\text {bc }}$ & 3.25 & $<0.001$ & 0.166 & 0.443 \\
\hline$C D(\mu \mathrm{m})$ & $102.73^{b}$ & $101.15^{b}$ & $102.97^{b}$ & $102.74^{b}$ & $105.26^{a}$ & 0.35 & $<0.001$ & $<0.001$ & 0.594 \\
\hline $\mathrm{VH} / \mathrm{CD}(\mu \mathrm{m} / \mu \mathrm{m})$ & $6.87^{\mathrm{a}}$ & $6.56^{\mathrm{bc}}$ & $6.62^{b}$ & $6.53^{\text {cd }}$ & $6.45^{d}$ & 0.03 & $<0.001$ & 0.065 & 0.038 \\
\hline \multicolumn{10}{|l|}{ Ileum } \\
\hline $\mathrm{VH}(\mu \mathrm{m})$ & $444.13^{\mathrm{ab}}$ & $334.46^{c}$ & $378.85^{b c}$ & $435.16^{\mathrm{ab}}$ & $478.90^{\mathrm{a}}$ & 14.94 & 0.012 & 0.001 & 0.662 \\
\hline$C D(\mu m)$ & $98.07^{\mathrm{a}}$ & $62.67^{c}$ & $62.90^{c}$ & $75.23^{\mathrm{bc}}$ & $87.63^{\mathrm{ab}}$ & 3.27 & $<0.001$ & $<0.001$ & 0.195 \\
\hline $\mathrm{VH} / \mathrm{CD}(\mu \mathrm{m} / \mu \mathrm{m})$ & 5.12 & 5.68 & 6.39 & 6.05 & 5.82 & 0.21 & 0.425 & 0.750 & 0.544 \\
\hline
\end{tabular}

Results are represented as the mean value $\pm \operatorname{SEM}(n=8)$.

SEM, standard error of the mean; ANOVA, analysis of variance; $V H$, villus height; $C D$, crypt depth; $V H / C D$, the ratio of villus height to crypt depth.

1) NC, a basic normal corn-soybean diet; CS, a corn-soybean-based diet supplementation with 20\% corn starch (CS); $4 \%$ RS, $8 \%$ RS, and $12 \%$ RS, the corn-soybean-based diets supplementation with $4 \%, 8 \%$, and $12 \%$ corn resistant starch (RS), respectively.

${ }^{2)}$ Orthogonal polynomial contrast was used to determine linear and quadratic effects of increasing concentrations of resistant starch in CS and RS diets.

a-d Means in a row without a common superscript letter significantly differ $(p<0.05)$.

Effects on short-chain fatty acids concentration in cecal digesta

In comparison with the control group, higher concentrations of acetate and butyrate were found in the CS and all RS treatments, as well as a higher propionate concentration was present in birds treated with $8 \% \mathrm{RS}$ and $12 \% \mathrm{RS}$ diets $(p<0.05$, Table 7). Furthermore, propionate concentrations were increased linearly with the increase of dietary RS level $(\mathrm{p}<0.05)$.

Immunohistochemical assessment of proliferating cell nuclear antigen

PCNA immunoreactivity was observed in duodenum, jejunum and ileum of broilers (Table 8, Figure 2). The percentage of duodenal PCNA-positive cells was higher in $12 \%$ RS group than that of the control $(\mathrm{p}<0.01)$. Feeding CS and RS treated diets increased the percentage of duodenal PCNA-positive cells in jejunum, and the birds only fed with $8 \%$ RS and $12 \%$ RS diets had an increased ileal percentage of PCNA-positive cells, compared to the control $(\mathrm{p}<0.01)$. Furthermore, the percentage of PCNA-positive cells in duodenum and ileum were increased linearly by feeding RS treated diets to broilers $(\mathrm{p}<0.01)$.

\section{Mucin glycoproteins and tight junction proteins} mRNA expression levels in jejunal mucosa

The mucin 1 mRNA expressions in $8 \%$ RS and $12 \%$ RS groups and the claudin 1 mRNA expressions in CS and RS groups were lower than those of $\mathrm{NC}$ group ( $<<0.05$, Figure 3$)$. The mRNA expression of mucin 1 was decreased linearly in response to the increased dietary RS level $(\mathrm{p}<0.05)$.

\section{Notch signal pathway mRNA expression levels in} jejunum mucosa

According to Figure 4, the mRNA expression of Notch1 was increased by feeding $4 \%$ RS and $12 \%$ RS diets compared to control $(p<0.05)$. Birds from RS groups exhibited higher mRNA expression of delta like canonical Notch ligand 4 (DLL4), and the mRNA expression of hes family bHLH transcription factor 1 (Hes1) was merely increased in RS treated groups, compared with the NC group $(\mathrm{p}<0.05)$. Additionally, feeding increased RS diets linearly up-regulated the mRNA expressions of Notch1 and Hes $1(\mathrm{p}<0.01)$.

\section{Plasma diamine oxidase activity and D-lactic acid concentration}

There was no significant difference on the plasma DAO activities and D-lactic acid concentration among NC, CS, and all RS groups (Table 9).

\section{DISCUSSION}

Corn is the most used cereal grain in the diets of intensively reared poultry, and CS contributes about $60 \%$ of the apparent metabolisable energy content of poultry feeds [22]. The RS content is always higher in the CS with a higher content of amylose [23]. Due to the indigestibility of RS, animal growth performance is often decreased when feeding corn with high RS ratio, Bergh et al [24] reported that broiler chickens fed with a high amylose diet exhibit a decreased BW, feed intake and an increased F/G ratio. A similar result was obtained from the present study, all CS and RS groups had a lower feed intake and BW gain as well as a higher F/G ratio com- 


\section{Duodenum}

\section{Jejunum}

\section{Ileum}

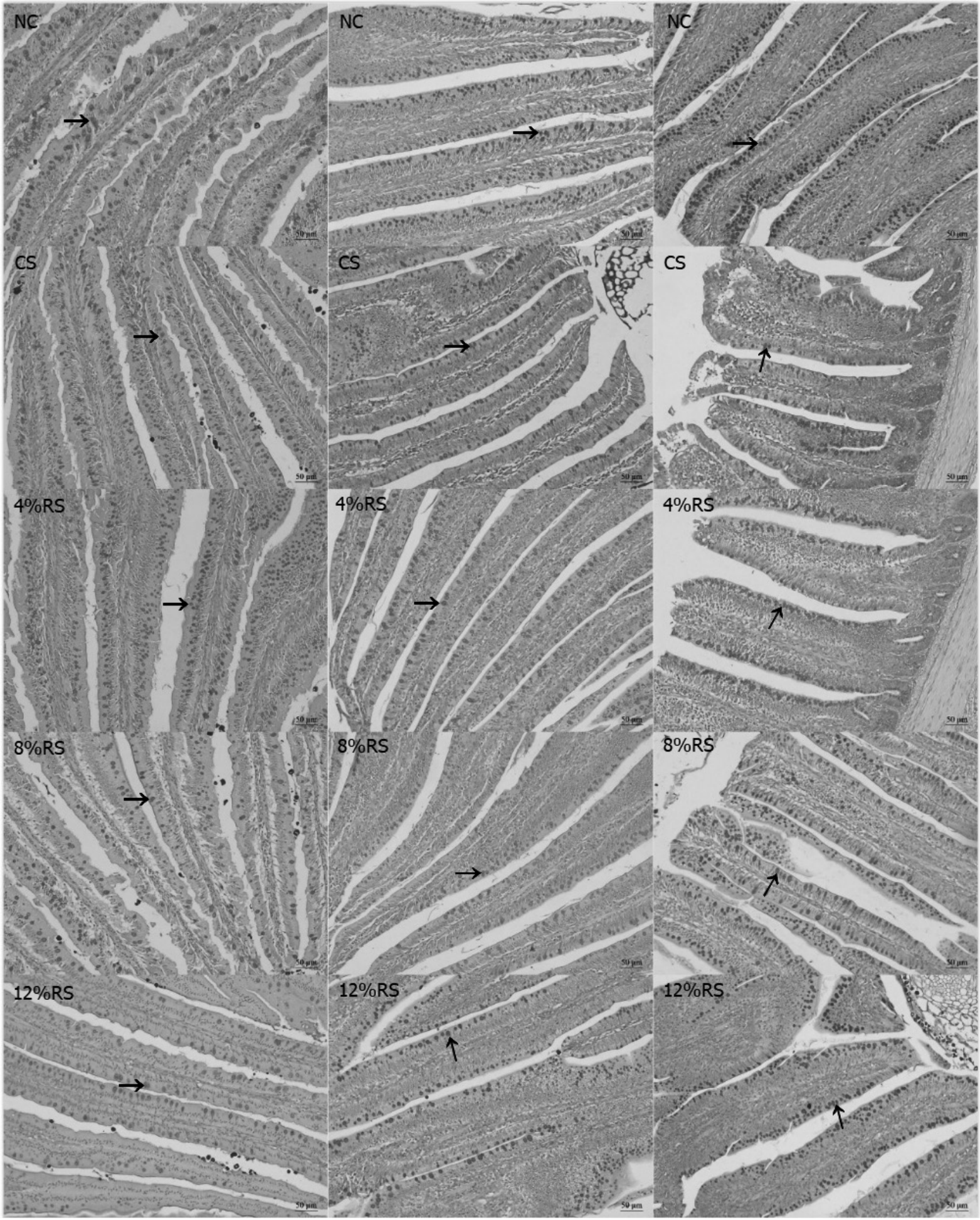

Figure 1. The periodic acid-Schiff staining of goblet cells in duodenum, jejunum and ileum villus of 21-day-old broilers (Arrows point to goblet cells). NC, a basic normal corn-soybeandiet; CS, a corn-soybean-based diet supplementation with 20\% corn starch (CS); 4\% RS, $8 \%$ RS, and $12 \%$ RS, the corn-soybean-based diets supplementation with $4 \%, 8 \%$, and $12 \%$ corn resistant starch (RS), respectively. Image, magnification at $\times 200$.

pared with the NC group. One reason for this may be the supplementation of RS in diets can effectively increase the concentrations of peptide YY and glucagon-like peptide-1
[25,26], these hormones usually can suppress appetite and reduce food intake, further decreasing weight gain [27]. In addition, our previous study also found that RS significantly 
Table 6. Effect of corn resistant starch on the intestinal goblet cell density of 21-day-old broilers

\begin{tabular}{|c|c|c|c|c|c|c|c|c|c|}
\hline \multirow{2}{*}{ Items } & \multicolumn{5}{|c|}{ Treatments $^{1)}$} & \multirow{2}{*}{ SEM } & \multicolumn{3}{|c|}{ p-value } \\
\hline & NC & CS & $4 \%$ RS & $8 \% \mathrm{RS}$ & $12 \% \mathrm{RS}$ & & ANOVA & Linear $^{2)}$ & Quadratic ${ }^{2)}$ \\
\hline Duodenum (n/per $100 \mu \mathrm{m}$ villus) & $6.71^{\mathrm{a}}$ & $6.38^{\mathrm{ab}}$ & $5.79^{b c}$ & $5.67^{b c}$ & $5.31^{d}$ & 0.15 & 0.009 & 0.166 & 0.053 \\
\hline Jejunum (n/per $100 \mu$ m villus) & 7.50 & 6.75 & 6.71 & 6.64 & 7.08 & 0.11 & 0.061 & 0.480 & 0.371 \\
\hline Ileum (n/per $100 \mu$ m villus) & 7.07 & 7.30 & 7.00 & 7.43 & 7.44 & 0.08 & 0.290 & 0.442 & 0.024 \\
\hline
\end{tabular}

Results are represented as the mean value $\pm \operatorname{SEM}(n=8)$.

SEM, standard error of the mean; ANOVA, analysis of variance.

1) NC, a basic normal corn-soybean diet; CS, a corn-soybean-based diet supplementation with 20\% corn starch (CS); 4\% RS, 8\% RS, and 12\% RS, the corn-soybean-based diets supplementation with $4 \%, 8 \%$, and $12 \%$ corn resistant starch (RS), respectively.

${ }^{2)}$ Orthogonal polynomial contrast was used to determine linear and quadratic effects of increasing concentrations of resistant starch in CS and RS diets.

a-d Means in a row without a common superscript letter significantly differ $(p<0.05)$.

Table 7. Effect of corn resistant starch on the concentrations of short chain fatty acids in cecal digesta of 21-day-old broilers

\begin{tabular}{|c|c|c|c|c|c|c|c|c|c|}
\hline \multirow{2}{*}{ Items } & \multicolumn{5}{|c|}{ Treatments ${ }^{1)}$} & \multirow{2}{*}{ SEM } & \multicolumn{3}{|c|}{$p$-value } \\
\hline & NC & CS & $4 \% \mathrm{RS}$ & $8 \% \mathrm{RS}$ & $12 \%$ RS & & AVONA & Linear $^{2)}$ & Quadratic ${ }^{2)}$ \\
\hline Acetate $(\mu \mathrm{M} / \mathrm{g})$ & $30.55^{b}$ & $49.37^{a}$ & $48.67^{\mathrm{a}}$ & $49.61^{a}$ & $52.83^{\mathrm{a}}$ & 2.46 & 0.026 & 0.640 & 0.720 \\
\hline Propionate $(\mu \mathrm{M} / \mathrm{g})$ & $1.84^{c}$ & $2.14^{b c}$ & $3.09^{\mathrm{abc}}$ & $3.40^{\mathrm{ab}}$ & $3.85^{\mathrm{a}}$ & 0.21 & 0.011 & 0.009 & 0.536 \\
\hline Butyrate $(\mu \mathrm{M} / \mathrm{g})$ & $2.62^{b}$ & $5.42^{\mathrm{a}}$ & $5.64^{\mathrm{a}}$ & $6.19^{a}$ & $6.40^{\mathrm{a}}$ & 0.29 & $<0.001$ & 0.170 & 0.978 \\
\hline
\end{tabular}

Results are represented as the mean value \pm SEM $(n=8)$

SEM, standard error of the mean; ANOVA, analysis of variance.

1) NC, a basic normal corn-soybean diet; CS, a corn-soybean-based diet supplementation with 20\% corn starch (CS); $4 \%$ RS, $8 \%$ RS, and 12\% RS, the corn-soybean-based diets supplementation with $4 \%, 8 \%$, and $12 \%$ corn resistant starch (RS), respectively.

${ }^{2)}$ Orthogonal polynomial contrast was used to determine linear and quadratic effects of increasing concentrations of resistant starch in CS and RS diets.

${ }^{a-c}$ Means in a row without a common superscript letter significantly differ $(p<0.05)$.

Table 8. Effect of corn resistant starch on the percentage of PCNA-positive cells in the intestinal villus of 21-day-old broilers

\begin{tabular}{|c|c|c|c|c|c|c|c|c|c|}
\hline \multirow{2}{*}{ Items } & \multicolumn{5}{|c|}{ Treatments ${ }^{1)}$} & \multirow{2}{*}{ SEM } & \multicolumn{3}{|c|}{$\mathrm{p}$-value } \\
\hline & NC & CS & $4 \% \mathrm{RS}$ & $8 \% \mathrm{RS}$ & $12 \% \mathrm{RS}$ & & AVONA & Linear ${ }^{2)}$ & Quadratic ${ }^{2)}$ \\
\hline Duodenum (percentage of PCNA-positive cells, \%) & $16.97^{\mathrm{bc}}$ & $13.12^{d}$ & $15.63^{\text {cd }}$ & $20.03^{\mathrm{ab}}$ & $21.24^{\mathrm{a}}$ & 0.63 & $<0.001$ & $<0.001$ & 0.562 \\
\hline Jejunum (percentage of PCNA-positive cells, \%) & $18.78^{b}$ & $21.54^{\mathrm{a}}$ & $23.37^{\mathrm{a}}$ & $21.92^{\mathrm{a}}$ & $23.52^{\mathrm{a}}$ & 0.40 & $<0.001$ & 0.247 & 0.707 \\
\hline Ileum (percentage of PCNA-positive cells, \%) & $25.81^{b}$ & $26.85^{b}$ & $28.13^{b}$ & $34.09^{a}$ & $33.42^{\mathrm{a}}$ & 0.85 & 0.001 & 0.002 & 0.610 \\
\hline
\end{tabular}

Results are represented as the mean value \pm SEM $(n=8)$.

PCNA, proliferating cell nuclear antigen; SEM, standard error of the mean; ANOVA, analysis of variance.

1) NC, a basic normal corn-soybean diet; CS, a corn-soybean-based diet supplementation with 20\% corn starch (CS); $4 \%$ RS, $8 \%$ RS, and 12\% RS, the corn-soybean-based diets supplementation with $4 \%, 8 \%$, and $12 \%$ corn resistant starch (RS), respectively.

${ }^{2)}$ Orthogonal polynomial contrast was used to determine linear and quadratic effects of increasing concentrations of resistant starch in CS and RS diets.

a-d Means in a row without a common superscript letter significantly differ $(p<0.05)$.

decreased nutrient digestibility [28], which might also contribute to a lower BW gain.

Intestinal tract is the main site for digestion and absorption of nutrients. In the present study, we found that birds fed CS and RS diets had higher relative lengths of small intestine (duodenum, jejunum, and ileum) than those fed the control diet. This most likely enabled the chickens to absorb nutrients efficiently as the digesta would take longer to pass through the intestine as the absorption area become larger. Meanwhile, it should be noted that intestinal absorptive capacity depends more on overall villus height [29]. Unexpectedly, all RS treatments significantly decreased jejunal VH in broilers. The result was opposite to the finding by Qin et al [30] who found that RS significantly improved the intestinal mor- phology of ducks. The main reason may be that ducks have stronger intestinal microbial fermentation capacity than chickens and can use more indigestible carbohydrates [31]. A lower villus would decrease the areas of nutrient absorption. Hence, we speculated that RS may decrease the digestion and absorption of nutrients in the jejunum. The jejunal VH/CD was decreased linearly in response to the increase of dietary RS level, which again proved that the higher dietary RS level was, the worse nutrients digestion and absorption ability would be.

The RS is resistant to degradation in the small intestine but metabolized by microbes in the hindgut, where they are fermented into SCFAs, including acetic acid, propionic acid and butyric acid [5]. Among the SCFAs, butyrate has been investigated most extensively. Butyrate is the primary energy 


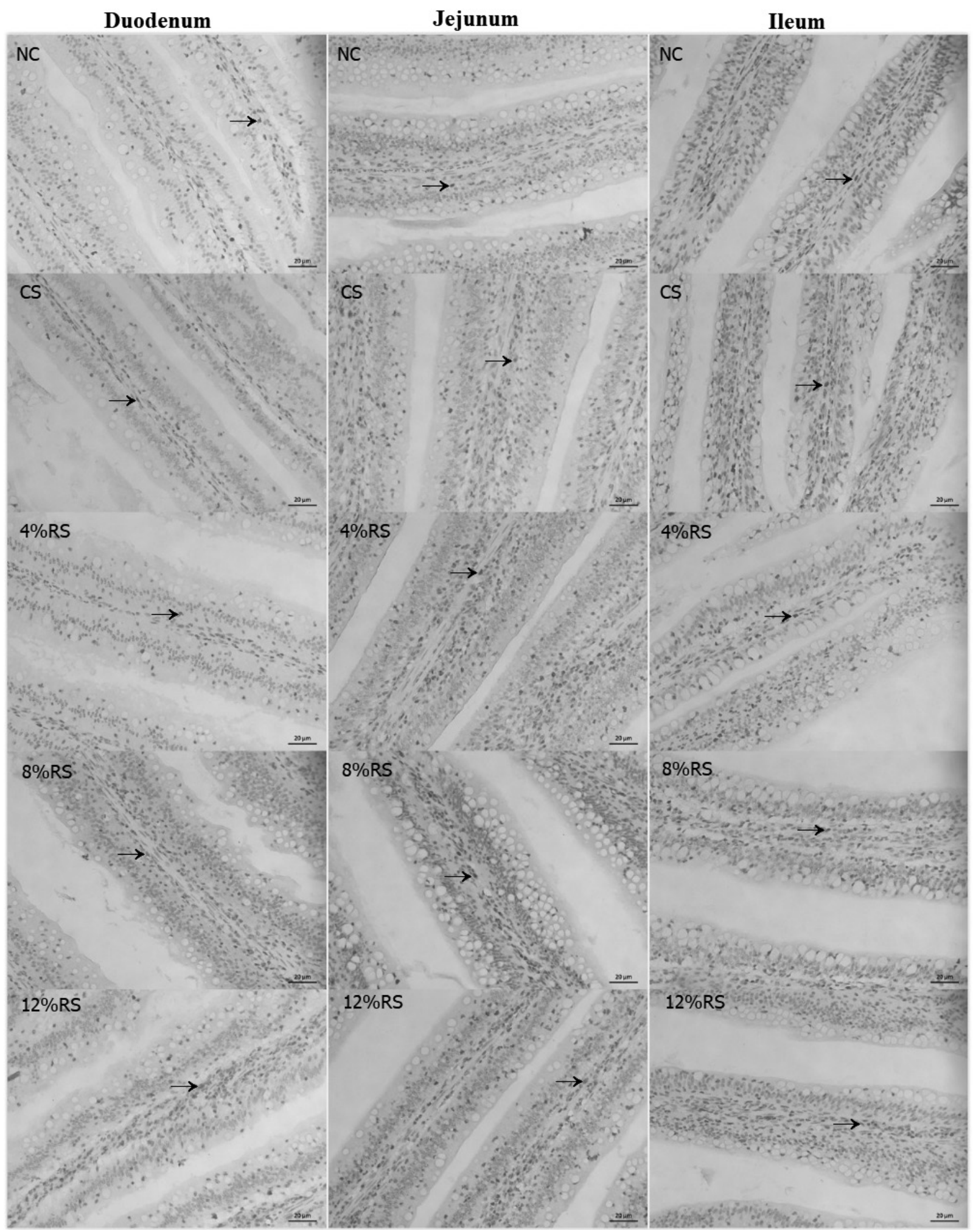

Figure 2. The PCNA immunohistochemical assessment of duodenum, jejunum and ileum villus of 21-day-old broilers (Arrows point to PCNA-positive cells).NC, a basic normal corn-soybeandiet; CS, a corn-soybean-based diet supplementation with 20\% corn starch (CS); 4\% RS, 8\% RS, and 12\% RS, the corn-soybean-based diets supplementation with $4 \%, 8 \%$, and $12 \%$ corn resistant starch (RS), respectively; PCNA, proliferating cell nuclear antigen. Image, magnification at $\times 400$.

source for epithelial cells and functions as a histone deacetylase inhibitor [32], which alters the expression of many genes with diverse functions, some of which include cell prolifera- tion and differentiation [15]. In this study, all RS treatments increased the butyric acid concentration, which may promote epithelial cell proliferation. PCNA plays an essential role in 

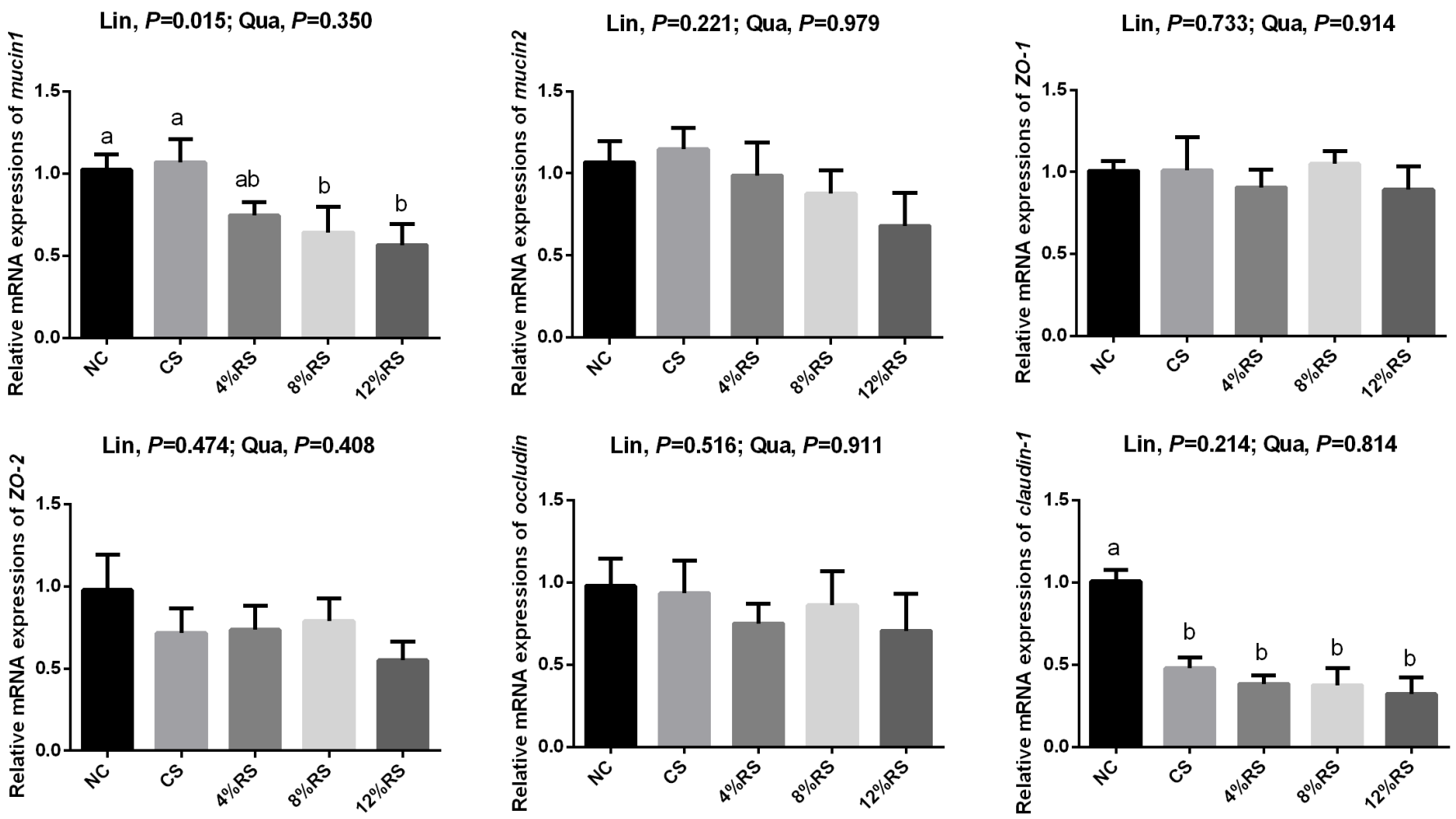

Figure 3. Effects of corn resistant starch on the relative mRNA expressions of mucin1, mucin2, claudin-1, occludin, Z0-1, and Z0-2 in jejunal mucosa of 21-day-old broilers. Results are represented as the mean value \pm standard error of the mean $(n=8)$. ${ }^{a, b}$ Means in a row without a common superscript letter significantly differ $(p<0.05)$. NC, a basic normal corn-soybean diet; CS, a corn-soybean-based diet supplementation with 20\% corn starch (CS); 4\% RS, 8\% RS, and 12\% RS, the corn-soybean-based diets supplementation with 4\%, 8\%, and 12\% corn resistant starch (RS), respectively; ZO-1, zonula occludens-1; ZO-2, zonula occludens-2.

DNA replication, DNA repair and cell cycle control [33,34], and has a broad correlation with mitotic activity, for which it can be used as a marker for cell proliferation in intestinal mucosa. The current result showed that $12 \%$ RS treatments increased the percentage of PCNA-positive cells of the villus in duodenum, jejunum and ileum. This suggested that high dietary RS can promote the proliferation of intestinal epithelium cells of broilers. As mentioned above, the intestinal mucosal epithelium consists of four main cell types-absorptive enterocytes, goblet cells, Paneth cells, and enteroendocrine cells [17]. Intestinal goblet cells are responsible for the release of mucins into the intestinal lumen. We wondered if the increased epithelium proliferation would affect the differentiation of various cell types. Therefore, the goblet cells density in the small intestine was observed. The result showed that all RS treatments decreased the duodenal and jejunal goblet cells density. It is intestinal epithelium stem cells residing in the base of crypts that give rise to a transit-amplifying population of cells that undergo rapid proliferation and differentiation into the various intestinal epithelial cell subsets [15]. The decreased goblet cells indicated that RS may suppress the goblet cell differentiation and promote other cells type, which may have a profound impact on the physiological functions of the intestine
Notch signaling pathway plays a central role in cell fate differentiation towards secretory versus non-secretory lineage [15]. Previous studies have found that Notch inhibition led to precocious differentiation of epithelial progenitors into secretory cell types, including large numbers of cells that expressed both Paneth and goblet cell [12]. Conversely, activation of Notch signaling in intestinal epithelium will repress secretory cell differentiation [2]. To determine whether RS affect the development of intestinal epithelium by regulating the Notch pathway, the relative mRNA expressions of Notch1, Notch2, DLL1, DLL4, Hes1, and Atoh1 in jejunal mucosa were assessed. We found that the Notch1, DLL4, and Hes1 mRNA expressions of jejunal mucosa of the all RS groups were higher than those of the NC group. These results demonstrated that RS activated the Notch pathway, which may be responsible for the reduction of secretory goblet cells.

The mucus layer covers the entire gastrointestinal tract, mainly because of the secretory products of goblet cells [17]. Mucin 1 and mucin 2 are membrane-bound mucins and gelforming secretory mucins, respectively. They provide the host's first line of defense against endogenous or exogenous attack and microbial attachment and invasion, but allow nutrients to pass through $[17,35]$. In current study, dietary RS reduced the density of duodenal goblet cells, which may lead to a de- 

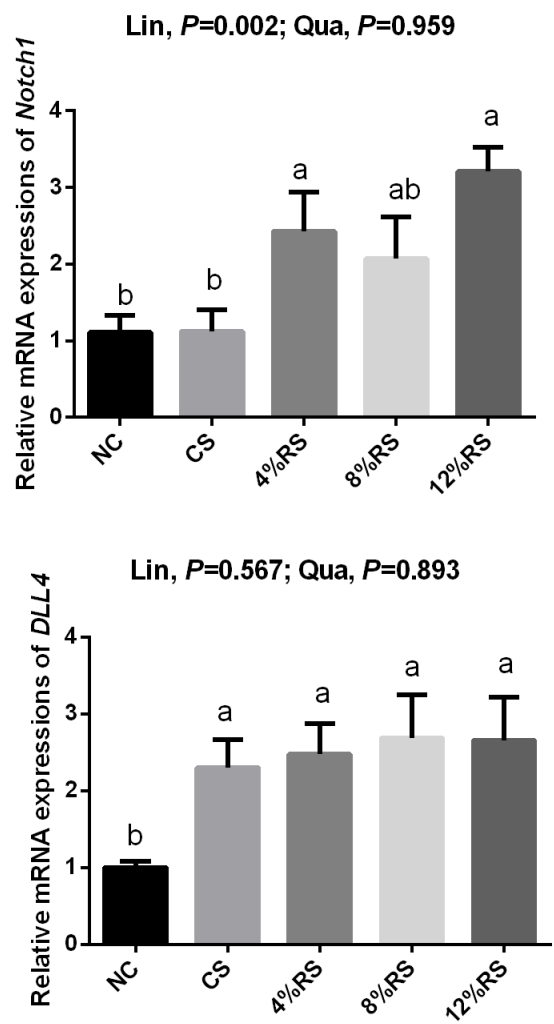

Lin, $P=0.994 ;$ Qua, $P=0.046$
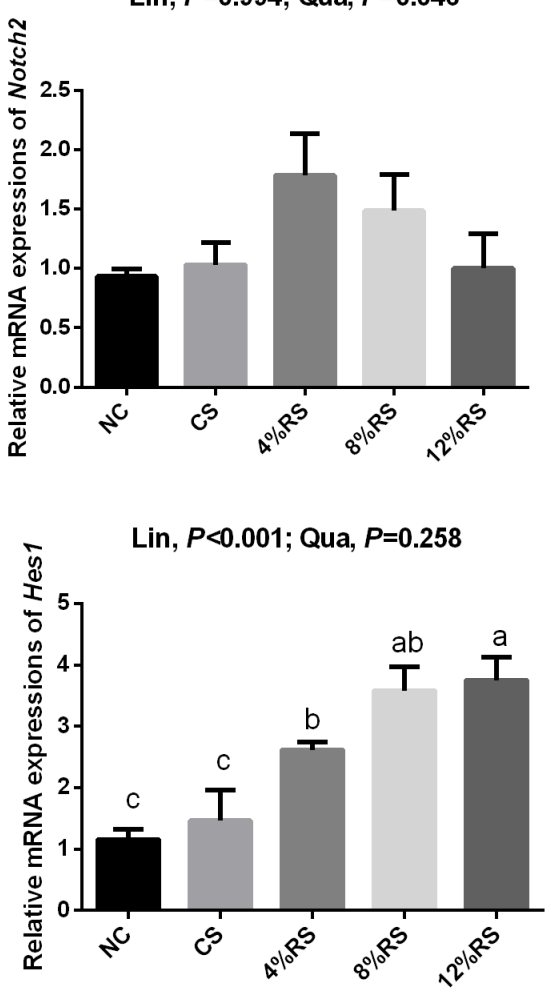

Lin, $P=0.694 ;$ Qua, $P=0.094$
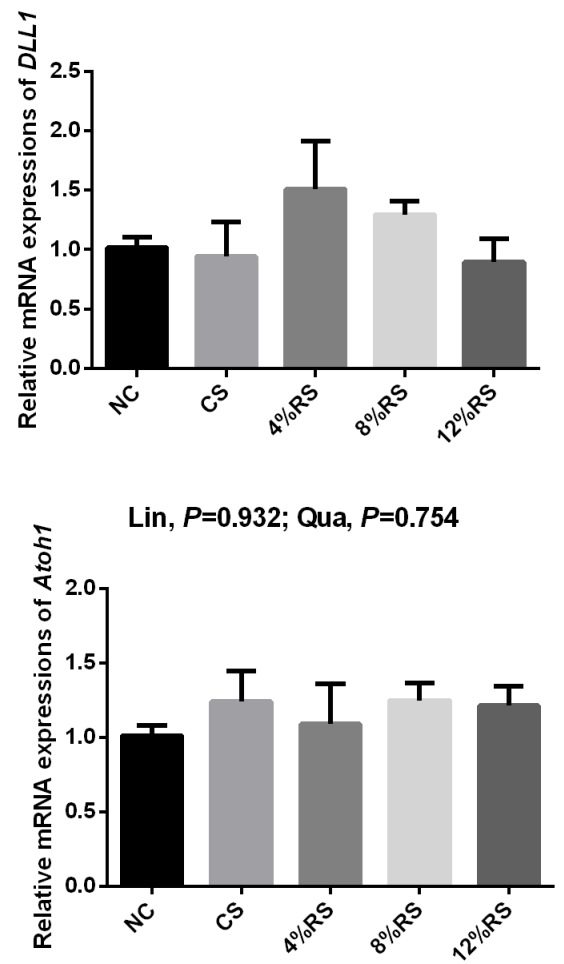

Figure 4. Effects of corn resistant starch on the relative mRNA expressions of notch1, notch2, DLL1, DLL4, Hes1, and Atoh1 in jejunal mucosa of 21-day-old broilers. Results are represented as the mean value \pm standard error of the mean $(n=8) .{ }^{a-c}$ Means in a row without a common superscript letter significantly differ $(p<0.05)$. NC, a basic normal corn-soybean diet; CS, a corn-soybean-based diet supplementation with 20\% corn starch (CS); 4\% RS, 8\% RS, and 12\% RS, the corn-soybean-based diets supplementation with 4\%,8\%, and 12\% corn resistant starch (RS), respectively. DLL1, delta like canonical Notch ligand 1; DLL4, delta like canonical Notch ligand 4; Hes1, hes family bHLH transcription factor 1; Atoh1, atonal homolog 1.

Table 9. Effects of corn resistant starch on the plasma diamine oxidase activity and D-lactic acid concentration of 21-day-old broilers

\begin{tabular}{|c|c|c|c|c|c|c|c|c|c|}
\hline \multirow{2}{*}{ Items } & \multicolumn{5}{|c|}{ Treatments ${ }^{1)}$} & \multirow{2}{*}{ SEM } & \multicolumn{3}{|c|}{ p-value } \\
\hline & NC & CS & $4 \% \mathrm{RS}$ & $8 \% \mathrm{RS}$ & $12 \%$ RS & & AVONA & Linear $^{2)}$ & Quadratic $^{2)}$ \\
\hline DAO (U/L) & 21.71 & 19.61 & 22.29 & 21.01 & 19.70 & 0.74 & 0.754 & 0.671 & 0.730 \\
\hline D-lactic acid (nmol/mL) & 10.11 & 11.33 & 11.4 & 10.18 & 9.93 & 0.72 & 0.952 & 0.806 & 0.514 \\
\hline
\end{tabular}

Results are represented as the mean value $\pm \operatorname{SEM}(n=8)$.

SEM, standard error of the mean; ANOVA, analysis of variance; DAO, diamine oxidase.

1) NC, a basic normal corn-soybean diet; CS, a corn-soybean-based diet supplementation with 20\% corn starch (CS); 4\% RS, 8\% RS, and 12\% RS, the corn-soybean-based diets supplementation with $4 \%, 8 \%$, and $12 \%$ corn resistant starch (RS), respectively.

${ }^{2)}$ Orthogonal polynomial contrast was used to determine linear and quadratic effects of increasing concentrations of resistant starch in CS and RS diets.

crease in mucin production. Therefore, we detected the relative mRNA expressions of mucin 1 and mucin 2 in jejunal mucosa. Not surprisingly, the relative mRNA expressions of mucin 1 were decreased in $8 \%$ RS and $12 \%$ RS groups, which may have a negative effect on intestinal barrier function.

The mucosal barrier is mainly divided into mechanical barriers, biological barriers, chemical barriers and immunological barriers [36]. The mechanical barrier plays an important role in absorbing nutrients and resisting invasion of enteric pathogens. While the mechanical barrier is formed by epithelial cells (e.g. absorptive cells and goblet cells) and the junctional complex, consisting of tight junctions (TJ), adherens junctions, gap junctions, and desmosomes $[3,37]$. Occludin, claudins and zonula occludens $(\mathrm{ZO})$ are the most important components in the regulation of epithelial barrier function among TJ. Therefore, we also examined the relative mRNA expressions of claudin-1, occludin, ZO-1, and $Z O-2$ in jejunal mucosa. Similarly, the relative mRNA expression of claudin-1 and ZO-1 were also decreased. It's common sense that intestinal permeability is managed by $\mathrm{TJ}$ [38], so the decreased TJ might alter intestinal permeability. 
Finally, DAO and D-lactic acid in plasma were measured to test intestinal permeability. The DAO is an enzyme that catalyzes the oxidation of diamines. It is normally abundant in intestinal mucosa, but rarely in other tissues. When intestinal mucosa is damaged, DAO activity in the blood increases. Hence, serum DAO activity might be a good marker for intestinal mucosal integrity [39]. In this study, there was no significant difference in the plasma DAO activities among all groups, indicating that although dietary RS inhibited the development of duodenal goblet cell, mucins and TJ, but it was not enough to damage intestinal permeability. In addition, $\mathrm{D}$-lactic acid is the fermentation product of various bacteria in intestinal tract. Like DAO, the concentration of plasma Dlactic acid will increase when the intestinal mucosa is damaged. Hence, D-lactic acid can also be used as a marker for intestinal mucosal integrity. However, there was also no significant difference in the plasma D-lactic acid concentration in all groups. This again demonstrates that mucosal permeability has not been impaired despite the goblet cell development and barrier function were inhibited.

\section{CONCLUSION}

In summary, dietary RS can impair intestinal morphology and barrier functions. The molecular mechanisms of the impaired barrier functions could be due to the increase of intestinal mucosa cell proliferation, which causes an inhibited development of goblet cells by activating notch pathway and results in decreased mucins and TJ mRNA expressions.

\section{CONFLICT OF INTEREST}

We certify that there is no conflict of interest with any financial organization regarding the material discussed in the manuscript.

\section{ACKNOWLEDGMENTS}

This study was financially supported by the National Key Research and Development Program of China (2017YFD 0500505), the Earmarked Fund for Jiangsu Agricultural Industry Technology System (JATS[2020]407) and the Jiangsu Overseas Visiting Scholar Program for University Prominent Young \& Middle-aged Teachers and Presidents (2018).

\section{REFERENCES}

1. Montagne L, Pluske JR, Hampson DJ. A review of interactions between dietary fibre and the intestinal mucosa, and their consequences on digestive health in young non-ruminant animals. Anim Feed Sci Technol 2003;108:95-117. https://doi. org/10.1016/S0377-8401(03)00163-9
2. Fre $S$, Huyghe M, Mourikis $P$, et al. Notch signals control the fate of immature progenitor cells in the intestine. Nature 2005;435:964-8. https://doi.org/10.1038/nature03589

3. Turner JR. Intestinal mucosal barrier function in health and disease. Nat Rev Immunol 2009;9:799-809. https://doi.org/ 10.1038/nri2653

4. Englyst HN, Kingman SM, Cummings JH. Classification and measurement of nutritionally important starch fractions. Eur J Clin Nutr 1992;46(Suppl 2):S33-50.

5. Nugent AP. Health properties of resistant starch. Nutr Bull 2005;30:27-54. https://doi.org/10.1111/j.1467-3010.2005. 00481.x

6. Bird A, Conlon M, Christophersen C, et al. Resistant starch, large bowel fermentation and a broader perspective of prebiotics and probiotics. Benef Microbes 2010;1:423-31. https://doi. org/10.3920/BM2010.0041

7. Alfa MJ, Strang D, Tappia PS, et al. A randomized trial to determine the impact of a digestion resistant starch composition on the gut microbiome in older and mid-age adults. Clin Nutr 2018;37:797-807. https://doi.org/10.1016/j.clnu. 2017.03.025

8. Hedemann MS, Knudsen KEB. Resistant starch for weaning pigs-Effect on concentration of short chain fatty acids in digesta and intestinal morphology. Livest Sci 2007;108:1757. https://doi.org/10.1016/j.livsci.2007.01.045

9. Ribeiro RS, Pinho M, Falcão-Cunha L, et al. The use of chestnuts (Castanea sativa Mill.) as a source of resistant starch in the diet of the weaned piglet. Anim Feed Sci Technol 2013; 182:111-20. https://doi.org/10.1016/j.anifeedsci.2013.04.009

10. Simon TC, Gordon JI. Intestinal epithelial cell differentiation: new insights from mice, flies and nematodes. Curr Opin Genet Dev 1995;5:577-86. https://doi.org/10.1016/0959437X(95)80026-3

11. Stanger BZ, Datar R, Murtaugh LC, et al. Direct regulation of intestinal fate by Notch. Proc Natl Acad Sci USA 2005;102: 12443-8. https://doi.org/10.1073/pnas.0505690102

12. Vandussen KL, Carulli AJ, Keeley TM, et al. Notch signaling modulates proliferation and differentiation of intestinal crypt base columnar stem cells. Development 2011;139:488-97. https://doi.org/10.1242/dev.070763

13. Mumm JS, Kopan R. Notch signaling: from the outside in. Dev Biol 2000;228:151-65. https://doi.org/10.1006/dbio.2000. 9960

14. Artavanis-Tsakonas S. Notch signaling: cell fate control and signal integration in development. Science 1999;284:770-6. https://doi.org/10.1126/science.284.5415.770

15. Van Der Flier LG, Clevers H. Stem cells, self-renewal, and differentiation in the intestinal epithelium. Annu Rev Physiol 2009;71:241-60. https://doi.org/10.1146/annurev.physiol. 010908.163145

16. Smirnov A, Tako E, Ferket PR, et al. Mucin gene expression and mucin content in the chicken intestinal goblet cells are 
affected by in ovo feeding of carbohydrates. Poult Sci 2006; 85:669-73. https://doi.org/10.1093/ps/85.4.669

17. Kim YS, Ho SB. Intestinal goblet cells and mucins in health and disease: recent insights and progress. Curr Gastroenterol Rep 2010;12:319-30. https://doi.org/10.1007/s11894-0100131-2

18. Kurokowa M, Lynch K, Podolsky DK. Effects of growth factors on an intestinal epithelial cell line: transforming growth factor $\beta$ inhibits proliferation and stimulates differentiation. Biochem Biophys Res Commun 1987;142:775-82. https://doi.org/10. 1016/0006-291X(87)91481-1

19. Uni Z, Geyra A, Ben-Hur H, et al. Small intestinal development in the young chick: crypt formation and enterocyte proliferation and migration. Br Poult Sci 2000;41:544-51. https://doi.org/10.1080/00071660020009054

20. Gabriel I, Lessire M, Mallet S, Guillot JF. Microflora of the digestive tract: critical factors and consequences for poultry. World Poult Sci J 2006;62:499-511. https://doi.org/10.1017/ S0043933906001115

21. Livak KJ, Schmittgen TD. Analysis of relative gene expression data using real-time quantitative PCR and the $2^{-\triangle \Delta C T}$ method. Methods 2001;25:402-8. https://doi.org/10.1006/meth.2001

22. Cowieson AJ. Factors that affect the nutritional value of maize for broilers. Anim Feed Sci Technol 2005;119:293-305. https:// doi.org/10.1016/j.anifeedsci.2004.12.017

23. Bird A R, Vuaran M, Brown I, et al. Two high-amylose maize starches with different amounts of resistant starch vary in their effects on fermentation, tissue and digesta mass accretion, and bacterial populations in the large bowel of pigs. Br J Nutr 2007;97(01):134-144. https://doi.org/10.1017/S0007114507 250433

24. Bergh MO, Razdan A, Åman P. Nutritional influence of broiler chicken diets based on covered normal, waxy and high amylose barleys with or without enzyme supplementation. Anim Feed Sci Technol 1999;78:215-26. https://doi. org/10.1016/S0377-8401(98)00281-8

25. Zhou J, Martin RJ, Tulley RT, et al. Dietary resistant starch upregulates total GLP-1 and PYY in a sustained day-long manner through fermentation in rodents. Am J Physiol Endocrinol Metab 2008;295:E1160-6. https://doi.org/10.1152/ ajpendo.90637.2008

26. Maki KC, Pelkman CL, Finocchiaro ET, et al. Resistant starch from high-amylose maize increases insulin sensitivity in overweight and obese men. J Nutr 2012;142:717-23. https:// doi.org/10.3945/jn.111.152975

27. De Silva A, Bloom SR. Gut hormones and appetite control: a focus on PYY and GLP-1 as therapeutic targets in obesity. Gut Liver 2012;6:10-20. https://doi.org/10.5009/gnl.2012.6. 1.10
28. Liu YS, Zhang YY, Li JL, et al. Growth performance, carcass traits and digestive function of broiler chickens fed diets with graded levels of corn resistant starch. Br Poult Sci 2020;61: 146-55. https://doi.org/10.1080/00071668.2019.1694137

29. Wijtten PJA, Langhout DJ, Verstegen MWA. Small intestine development in chicks after hatch and in pigs around the time of weaning and its relation with nutrition: a review. Acta Agric Scand A Anim Sci 2012;62:1-12. https://doi.org/10.10 80/09064702.2012.676061

30. Qin S, Zhang K, Applegate TJ, et al. Dietary administration of resistant starch improved caecal barrier function by enhancing intestinal morphology and modulating microbiota composition in meat duck. Br J Nutr 2020;123:172-81. https://doi.org/ 10.1017/S0007114519002319

31. Józefiak D, Rutkowski A, Martin SA. Carbohydrate fermentation in the avian ceca: a review. Anim Feed Sci Technol 2004;113:1-15. https://doi.org/10.1016/j.anifeedsci.2003.09. 007

32. Khan S, Jena GB. Protective role of sodium butyrate, a HDAC inhibitor on beta-cell proliferation, function and glucose homeostasis through modulation of p38/ERK MAPK and apoptotic pathways: study in juvenile diabetic rat. Chem Biol Interact 2014;213:1-12. https://doi.org/10.1016/j.cbi.2014.02. 001

33. Moldovan GL, Pfander B, Jentsch S. PCNA, the maestro of the replication fork. Cell 2007;129:665-79. https://doi.org/ 10.1016/j.cell.2007.05.003

34. Kelman Z. PCNA: structure, functions and interactions. Oncogene 1997;14:629-40. https://doi.org/10.1038/sj.onc. 1200886

35. Mcauley JL, Linden SK, Png CW, et al. MUC1 cell surface mucin is a critical element of the mucosal barrier to infection. J Clin Invest 2007;117:2313-24. https://doi.org/10.1172/JCI 26705

36.Sánchez de Medina F, Romero-Calvo I, Mascaraque C, et al. Intestinal inflammation and mucosal barrier function. Inflamm Bowel Dis 2014;20(12):2394-404. https://doi.org/10.1097/ MIB.0000000000000204

37. Peterson LW, Artis D. Intestinal epithelial cells: regulators of barrier function and immune homeostasis. Nat Rev Immunol 2014;14:141-53. https://doi.org/10.1038/nri3608

38. Suzuki T. Regulation of intestinal epithelial permeability by tight junctions. Cell Mol Life Sci 2013;70:631-59. https://doi. org/10.1007/s00018-012-1070-x

39. Kamei H, Hachisuka T, Nakao M, et al. Quick recovery of serum diamine oxidase activity in patients undergoing total gastrectomy by oral enteral nutrition. Am J Surg 2005;189: 38-43. https://doi.org/10.1016/j.amjsurg.2004.03.015 